\title{
Comparing the efficacy of biofeedback and balloon-assisted training in the treatment of dyssynergic defecation
}

\author{
Abbs Ali Pourmomeny MSc${ }^{1}$, Mohammad Hassan Emami MD², Mahboobeh Amooshahi BS ${ }^{1}$, Peyman Adibi MD²
}

\begin{abstract}
AA Pourmomeny, MH Emami, M Amooshahi, P Adibi. Comparing the efficacy of biofeedback and balloon-assisted training in the treatment of dyssynergic defecation. Can J Gastroenterol 2011;25(2):89-92.
\end{abstract}

BACKGROUND: Dyssynergic defecation does not respond appropriately to routine treatments for constipation. Recently, research has shown that biofeedback therapy is useful in anorectal dyssynergia. OBJECTIVE:To compare two treatment modalities for patients experiencing dyssynergic defecation.

METHODS: Sixty-five subjects with dyssynergic defecation were recruited and randomly allocated to one of two treatment groups: balloon defecation training and biofeedback therapy. In the first group, a balloon was inserted into the rectum and inflated by water injection so that the patient experienced the sensation of a full rectum and, thus, the need to defecate. The patient was subsequently asked to reject the balloon. In the biofeedback group, the pen electrode of an electromyographic biofeedback device was inserted into the rectum, with the patient subsequently being asked to increase abdominal pressure and relax the rectal muscles accordingly.

RESULTS: The findings showed a reduction in constipation in both groups. The ability to reject the balloon (volume and time) was significantly better in postintervention measurements; however, better results were found in the biofeedback arm of the study. Patient satisfaction after treatment reached $52 \%$ with balloon training and $79 \%$ in the biofeedback group. Reports of incomplete evacuation and the need for digit use during defecation remained constant after treatment in balloon-trained patients.

CONCLUSION: Biofeedback training appeared to be superior to balloon defecation training and resulted in measurable changes in subjective and objective variables of dyssynergia.

Key Words: Anorectal dyssynergia; Balloon; Biofeedback; Constipation bstructed defecation, as an isolated disorder, affects approximately $7 \%$ of the population (1). On the other hand, anorectal dyssynergia was reported to be present in $28 \%$ of referred cases of constipation (2). Many of these cases may be missed at initial visits due to the lack of appropriate history taking and physical evaluation. The disorder is due, in large part, to inappropriate muscular contraction or relaxation during straining and stool evacuation manoeuvres. Dyssynergic defecation, the term currently used to describe this disorder, defines the problem better than the term anorectal dyssynergia because many of these patients lack other aspects of pelvic floor complaints such as urogenital symptoms (3). According to this definition, patients may experience anal sphincter contraction during rectal pressure increase (type I) or insufficient relaxation (ie, 20\% of baseline at this state [type II]) (4). In addition to somatic complaints, psychological problems and stressors may aggravate patient problems (5).

Although the results of previous studies have been inconsistent, neuromuscular training using biofeedback is now a proposed treatment modality for these groups of patients (6). The method is based on the

\section{Comparer l'efficacité du biofeedback et de la formation assistée par ballonnet dans le traitement de la défécation dyssynergique}

HISTORIQUE : La défécation dyssynergique ne répond pas convenablement aux traitements habituels de la constipation. Récemment, les recherches ont démontré l'utilité de la thérapie par biofeedback en cas de dyssynergie anorectale.

OBJECTIF : Comparer deux modalités thérapeutiques pour les patients présentant une défécation dyssynergique.

MÉTHODOLOGIE : Les chercheurs ont recruté 65 sujets présentant une défécation dyssynergique et les ont divisés au hasard entre deux groupes de traitement : la formation de la défécation par ballonnet et la thérapie par biofeedback. Au sein du premier groupe, un ballonnet était inséré dans le rectum et gonflé par injection d'eau afin que le patient ait l'impression d'avoir un rectum plein et ressente la nécessité de déféquer. Le patient devait ensuite rejeter le ballonnet. Au sein du groupe de biofeedback, l'électrode stylo d'un dispositif de biofeedback électromyographique était insérée dans le rectum, et le patient était invité à accroître la pression abdominale et à détendre les muscles rectaux en conséquence.

RÉSULTATS : Les résultats ont révélé une réduction de la constipation dans les deux groupes. La capacité de rejeter le ballonnet (volume et temps) s'était considérablement améliorée lors des mesures après l'intervention, mais les résultats étaient supérieurs dans le volet de biofeedback de l'étude. La satisfaction des patients atteignait $52 \%$ après la formation par ballonnet, et $79 \%$ après le biofeedback. Les rapports d'évacuation incomplète et de la nécessité d'utiliser les doigts pendant la défécation demeuraient constants après le traitement chez les patients formés par ballonnet.

CONCLUSION : La formation par biofeedback semble supérieure à la formation de la défécation par ballonnet et a entrainé des changements mesurables aux variables subjectives et objectives de dyssynergie.

generation and presentation of an audio or visual demonstration of voluntary bowel movement, and training the patient toward conscious voluntary change to achieve normal physiological movement. Other neuromuscular training using stool-like devices and balloon evacuation have also been proposed (7).

The prevalence of patients with dyssynergic defecation is higher in high-level referral centres. The present study compared the application of biofeedback and the routine method of patient education using balloon-assisted evacuation training.

\section{METHODS}

The present study was designed as an open-label clinical experiment with two parallel arms using before and after interventional measurements.

Patients were selected by two gastroenterologist collaborators of the study and referred to hospital based on treatment in the physiotherapy clinic.

${ }^{1}$ Department of Physiotherapy; ${ }^{2}$ Department of Internal Medicine, Isfahan University of Medical Sciences, Isfahan, Iran

Correspondence: Dr Peyman Adibi, Department of Internal Medicine, Gastroenterology Section, Isfahan University of Medical Sciences, Isfahan,

Iran. Telephone 98-311-7923060, fax 98-311-6687898, e-mail adibi@med.mui.ac.ir

Received for publication June 15, 2010. Accepted August 19, 2010 


\section{Sampling}

The patients were selected from two outpatient gastroenterology clinics in Isfahan, Iran: one in the private sector (Poursina Hakim) and the other from a governmental academic clinic (Noor). Patients who were diagnosed with dyssynergic defecation based on fulfillment of the Rome III criteria were evaluated according to recommended guidelines in face-to-face interviews by the caring physician; all patients experienced symptoms for more than six months (7). Routine treatments for chronic constipation were prescribed in all patients including increasing fluid intake, a high-fibre diet including vegetables and fruits, caffeine restriction, consumption of a bulking laxative (psyllium husk) and daily exercise (8). All patients underwent medical evaluation including history, physical examination and colonoscopy. Patients with a history of trauma to the pelvic area and/or radiation or surgery of this area were excluded.

Patients who did not respond or were unsatisfied with their defecation were referred to the physiotherapy department of an academic hospital.

All patients were informed about the study and treatment modalities before starting therapy. The selected cases were recruited after obtaining consent. The study was approved by the regional bioethics committee according to the national ethics codes of good clinical practice.

\section{Intervention}

Patients were allocated into one of two study arms by selecting every other case in each group. Treatment commenced with a briefing session for patient education and reassurance, which covered topics on anorectal anatomy, the physiology of defecation and the mechanism of pelvic floor coordination. For this purpose, a slide presentation and poster demonstration were used.

\section{Biofeedback-assisted training}

An electromyographic biofeedback apparatus (MYTO II, EBNeuro, Italy) and a rectal probe (Myomed, Enraf Nonius, The Netherlands) were used in the present study. With the patient in the left lateral position, the rectal probe was inserted in such a way that the electrodes were set on the internal and external anal sphincter, with the ground electrode attached to the patient's arm. As the patient viewed an isoelectric line tracing on a monitor, he/she was asked to comment on how the line altered with his/her rectal relaxation or contraction. The therapist informed the patient about the auditory and visual outputs of the device. The patient was asked to relax the pelvic floor muscles, contract the abdominal muscles and breathe for $30 \mathrm{~s}$, then to breathe deeply in such a way as to reduce the apparatus' voice output and flatten the isoelectric line. The patient was trained to gradually coordinate defecation manoeuvers. In a stepwise approach, the sensitivity of the apparatus was increased to maximize the patient's neuromuscular coordination abilities.

\section{Balloon-assisted training}

With the patient in the left lateral position, a Foley catheter was inserted $10 \mathrm{~cm}$ into the rectum. Fifty millilitres of water was subsequently injected into the balloon. The patient was asked to increase intra-abdominal pressure, relax the anal sphincter and strain the rectum. To prevent muscular fatigue, the effort continued for no longer than $3 \mathrm{~min}$. If evacuation did not develop, water was suctioned off gradually to a volume that enabled the patient to expel the balloon. The left lateral position with a flexed hip and knee was preferred to enable the therapist to have a good view of the pelvic area and to provide stability for the patient (9).

\section{Measurement}

Follow-up evaluation was performed one week after execution of the procedures. Before and after intervention, the Rome III criteria were evaluated by the examiner according to the patient's opinions. Patients' satisfaction with their defecation was also ranked on a three-point scale (low, moderate or high). The elapsed time to pass the balloon by straining and the highest volume expelled was measured in both groups (10). Long-term follow-up could not be achieved in the present study.

\section{Statistical analysis}

'Always' and 'often' responses to the Rome criteria were defined as positive. Acceptable patient defecation was defined as 'good' and 'moderate' according to responses to the satisfaction question. The $\chi^{2}$ test was used to compare the qualitative variables between and within the groups for the before and after measurements. Differences in mean balloon volume and the time needed for its evacuation, as well as the change in these variables after treatment were compared using the $t$ test between the two groups, and using the paired $t$ test within each group in pre- and post-test phases.

The data from all recruited patients were analyzed (intention-totreat), with differences considered to be statistically significant at $\mathrm{P}<0.05$.

\section{RESULTS}

Overall, the present study recruited 65 patients: 49 women $(75 \%)$ and 16 men (25\%), with a male to female ratio of $1: 3$. Thirty-one patients were allocated to the balloon-assisted training group, while the biofeedback group consisted of 34 patients. The mean age of the patients was 37 years, with no significant difference in the mean $( \pm$ SD) age between the balloon ( $36.8 \pm 10$ years) and biofeedback ( $38 \pm 12$ years) groups. At the beginning of the study, the mean time for balloon evacuation was $176 \mathrm{~s}$, while the mean volume of the evacuated balloon was $14.4 \mathrm{~mL}$ within the entire sample. Three patients were found to have slow colon transit time (ie, more than $70 \mathrm{~h}$ ). Patients in both groups reported a mean of 2.8 bowel movements per week.

According to the Rome criteria, 98\% of the patients experienced incomplete evacuation, $89 \%$ required straining and $62 \%$ reported digit or manual use to assist defecation. The changes in the Rome criteria of constipation are summarized in Table 1 . The relative frequency of positive reports of the criteria was significantly different in pre-and post-test evaluation in the entire sample. Regarding the two main criteria of incomplete evacuation and the need for manual manoeuvres, the results were significantly better in the biofeedback group $(\mathrm{P}<0.05)$. The relative frequency of the need for manual manoeuvres did not change in the balloon group $(\mathrm{P}>0.05)$ (Table 1$)$.

The biofeedback group also showed more acceptable results in balloon evacuation volume and time after treatment (Table 2). Although cumulative results showed a statistically significant change in the entire sample, the balloon evacuation time reached $176 \mathrm{~s}$ in the post-test phase from $177 \mathrm{~s}$ in the pre-test phase within the balloon-assisted training group (ie, no meaningful change), whereas with the same baseline mean, this variable was reduced to $159 \mathrm{~s}$ in the biofeedback group. To clarify this difference, subtraction of before and after measurements were compared between the two groups. The mean of the change was significantly higher in the biofeedback group. The change in balloon evacuation time for the biofeedback group was $16 \mathrm{~s}$ versus $1 \mathrm{~s}$ for the balloon-trained group $(\mathrm{P}=0.03)$. The volume of the balloon defecated by the patients was increased by $18.2 \mathrm{~mL}$ and $11.3 \mathrm{~mL}$ for the biofeedback and balloon-trained groups, respectively $(\mathrm{P}=0.02)$ (Table 2$)$.

When the patients were interviewed for their sense of satisfaction with their defecation status, $78 \%$ of the treated patients reported 'complete' or 'partial' satisfaction, with $18 \%$ and $46 \%$ in the biofeedbacktreated patients, and $19 \%$ and $58 \%$ for the balloon-assisted trained patients, respectively $(\mathrm{P}>0.05)$.

\section{DISCUSSION}

The present study reported a comparison between two treatment modalities for neuromuscular training of patients experiencing dyssynergic defecation. The prominent complaint of the patients was straining and incomplete evacuation, with slow-transit constipation found in only $5 \%$ of cases. 
TABLE 1

Relative frequency of patients fulfilling Rome criteria before and after intervention

\begin{tabular}{|c|c|c|c|c|c|c|}
\hline & \multicolumn{2}{|c|}{ Biofeedback } & \multicolumn{2}{|c|}{ Balloon } & \multicolumn{2}{|c|}{ Total } \\
\hline & Before & After & Before & After & Before & After \\
\hline Straining & $34(100)$ & $14(43)$ & $27(88)$ & $14(45)$ & 58 (89) & $27(44)$ \\
\hline Hard stool & $19(60)$ & $8(23)$ & $22(72)$ & $13(41)$ & $42(66)$ & $21(32)$ \\
\hline $\begin{array}{l}\text { Incomplete } \\
\text { evacuation }\end{array}$ & $33(96)$ & $13(37)$ & 31 (100) & $26(83)$ & $64(98)$ & $38(59)$ \\
\hline $\begin{array}{l}\text { Need for manual } \\
\text { manoeuvres }\end{array}$ & $24(70)$ & $9(27)$ & $17(55)$ & $17(55)$ & $40(62)$ & $27(41)$ \\
\hline $\begin{array}{l}\text { Fewer than three } \\
\text { passes per week }\end{array}$ & $27(80)$ & $9(27)$ & $23(76)$ & $12(40)$ & $51(78)$ & $22(34)$ \\
\hline
\end{tabular}

Data presented as $n(\%)$

Although both training methods had positive effects on patient outcomes, the comparative efficacy of biofeedback was highly superior to balloon-assisted neuromuscular training with respect to the quantitative variables of time and suitable volume of balloon evacuation. Although the treatment sessions were repeated six times in both groups, the differences can be explained, in part, by the need for repetitive balloon evacuation training at home, which may not have been as simple for some patients as others. We are aware of the limitations to and biases inherent in open-label studies; however, maximal efforts were made to keep the quality of the study in the present form.

Theoretically, neuromuscular training was included in both arms of the study; biofeedback-assisted training was based mostly on auditory and visual biofeedback to maintain better coordination of muscles, while balloon-assisted training was based on sensory biofeedback with the use of a stool-like device to stimulate appropriate defecation.

Wiesel et al (11), Chiotakakou-Faliakou et al (12) and Emmanuel and Kamm (13), in three separate but uncontrolled trials, used biofeedback for similar patients. Patients in the study by ChiotakakouFaliakou et al (12) reported a sense of well-being following biofeedback. The ratio of Wiesel et al's (11) cases was 79\%, and more than one-half of the group studied by Emmanuel and Kamm (13) reported more frequent bowel movements each week. Patient satisfaction with the treatment seemed to be high in our study, both in the entire sample and in each group. Our results were similar to those of Bleijenberg and Kuijpers (14), who divided patients into two similar trial arms, although the number of the cases (two groups of 11 patients) was lower than in our study, and also demonstrated a superior efficacy of biofeedback (14).
TABLE 2

Balloon expulsion testing (mean time to evacuation and mean volume of evacuated balloon before and after treatment)

\begin{tabular}{lccccccc}
\hline & \multicolumn{3}{c}{ Time, } & & \multicolumn{3}{c}{ Volume, $\mathrm{mL}$} \\
\cline { 2 - 4 } \cline { 7 - 8 } Group & Before & After & $\mathbf{P}$ & & Before & After & $\mathbf{P}$ \\
\hline Biofeedback & 175 & 159 & $<0.01$ & & 13.5 & 31.7 & $<0.01$ \\
Balloon & 177 & 176 & 0.53 & & 16.5 & 27.8 & $<0.01$ \\
Total & 176 & 168 & 0.24 & & 14.4 & 29.8 & $<0.01$ \\
\hline
\end{tabular}

In contrast to these reports, Koutsomanis et al (15) compared muscular training with biofeedback and found no significant difference, but finally recommended and insisted on muscular training for these patients.

Interestingly, in some studies, recruited patients were not included merely based on criteria of dyssynergic defecation but on criteria of constipation as a whole, with these nonhomogeneous groups of patients subsequently assigned to biofeedback. For example, the 55 good outcomes reported by Chiotakakou-Faliakou et al (12) were based on patients with constipation; however, in the study by Dailianas et al (16), only $30 \%$ of the patients could be classified as having dyssynergic defecation, with only $30 \%$ of these patients having an acceptable outcome.

Another important aspect of neuromuscular training is the longevity of treatment effects, especially given the long duration of patient complaints and symptoms before starting treatment. For example, Chiarioni et al (17) followed patients for 24 months and established a persistent effect of biofeedback at 71\%. Battaglia et al (7) also showed a remnant efficacy of greater than $50 \%$ after one year. We could not follow-up on our patients and cannot reliably comment on the stability of our intervention over time; however, we recommend the use of electromyographic biofeedback with auditory and visual outputs, although it requires well-trained personnel and an adequately equipped clinical setting.

\section{CONCLUSION}

Table 3 summarizes the systematic reviews and current knowledge regarding biofeedback in constipation (18-21). Almost all of the reviews concluded that biofeedback showed favourable results; however, there were few reports related to controlled studies and many were not comparative. Although our research had limitations, especially regarding follow-up, it was comparative and showed the superiority of biofeedback with nondevice-mediated muscle training. Clearly, there is a need to conduct a large-scale, multicentre study with uniform treatment modalities to establish competencies versus failures of biofeedback in a specific subgroup (ie, dyssynergic defecation) of patients.

\section{TABLE3}

An overview of systematic reviews regarding biofeedback effect in constipation

\begin{tabular}{|c|c|c|c|}
\hline Author (reference) & Studies, $\mathbf{n}$ & Comparability & Comment \\
\hline Ernst and Resch (18) & 11 & $\begin{array}{l}\text { Improvement in } 67 \% \text { of patients; greater } \\
\text { efficacy of EMG over manometry }\end{array}$ & $\begin{array}{l}\text { Lack of blinding; possibility of placebo effect; consistency in } \\
\text { outcomes even with inconsistency in designs }\end{array}$ \\
\hline Coulter et al (19) & 1 & No significant improvement in stool frequency & $\begin{array}{l}\text { The review discussed biofeedback in all fields of gastrointestinal } \\
\text { conditions in pediatric and adult groups }\end{array}$ \\
\hline Koh et al (20) & 7 & $\begin{array}{l}\text { Biofeedback induced sixfold more relief; } \\
\text { greater efficacy of EMG over non-EMG }\end{array}$ & $\begin{array}{l}\text { At least one methodological problem in each study; heterogeneity } \\
\text { in design }\end{array}$ \\
\hline Palsson et al (21) & 38 & Significant overall efficacy of the procedure & Lack of controlled trials; lack of suitable follow-up \\
\hline
\end{tabular}

EMG Electromyography

\section{REFERENCES}

1. D'Hoore A, Penninckx F. Obstructed defecation. Colorectal Dis 2003;5:280-7.

2. Nyam DC, Pemberton JH, Ilstrup DM, Rath DM. Long-term results of surgery for chronic constipation. Dis Colon Rectum 1997;40:273-9.

3. Bharucha AE, Wald A, Enck P, Rao S. Functional anorectal disorders. Gastroenterology 2006;130:1510-8.
4. Rao SS, Welcher KD, Leistikow JS. Obstructive defecation: A failure of rectoanal coordination. Am J Gastroenterol 1998;93:1042-50.

5. Rao SS, Tuteja AK, Vellema T, Kempf J, Stessman M. Dyssynergic defecation: Demographics, symptoms, stool patterns, and quality of life. J Clin Gastroenterol 2004;38:680-5. 
6. Bassotti G, Chistolini F, Sietchiping-Nzepa F, de Roberto G, Morelli A, Chiarioni G. Biofeedback for pelvic floor dysfunction in constipation. BMJ 2004;328:393-6.

7. Battaglia E, Serra AM, Buonafede G, et al. Long-term study on the effects of visual biofeedback and muscle training as a therapeutic modality in pelvic floor dyssynergia and slow-transit constipation. Dis Colon Rectum 2004;47:90-5.

8. Locke GR III, Pemberton JH, Phillips SF. AGA technical review on constipation. American Gastroenterological Association. Gastroenterology 2000;119:1766-78.

9. Meagher AP, Sun WM, Kennedy ML, Smart RC, Lubowski DZ. Biofeedback for anismus: Has placebo effect been overlooked? Colorectal Dis 1998;1:80-7.

10. Rao SS, Hatfield R, Soffer E, Rao S, Beaty J, Conklin JL. Manometric tests of anorectal function in healthy adults. Am J Gastroenterol 1999;94:773-83.

11. Wiesel PH, Dorta G, Cuypers P, et al. Patient satisfaction after biofeedback for constipation and pelvic floor dyssynergia. Swiss Med Wkly 2001;131:152-6.

12. Chiotakakou-Faliakou E, Kamm MA, Roy AJ, Storrie JB, Turner IC. Biofeedback provides long-term benefit for patients with intractable, slow and normal transit constipation. Gut 1998;42:517-21.

13. Emmanuel AV, Kamm MA. Response to a behavioural treatment, biofeedback, in constipated patients is associated with improved gut transit and autonomic innervation. Gut 2001;49:214-9.
14. Bleijenberg G, Kuijpers HC. Biofeedback treatment of constipation: A comparison of two methods. Am J Gastroenterol 1994;89:1021-6.

15. Koutsomanis D, Lennard-Jones JE, Roy AJ, Kamm MA. Controlled randomised trial of visual biofeedback versus muscle training without a visual display for intractable constipation. Gut 1995;37:95-9.

16. Dailianas A, Skandalis N, Rimikis MN, Koutsomanis D, Kardasi M, Archimandritis A. Pelvic floor study in patients with obstructive defecation: Influence of biofeedback. J Clin Gastroenterol 2000;30:176-80.

17. Chiarioni G, Salandini L, Whitehead WE. Biofeedback benefits only patients with outlet dysfunction, not patients with isolated slow transit constipation. Gastroenterology 2005;129:86-97.

18. Ernst E, Resch KL. A meta-analysis of biofeedback treatment for anismus. Eur J Phys Med 1995;5:157-9.

19. Coulter ID, Favreau JT, Hardy ML, Morton SC, Roth EA, Shekelle P. Biofeedback interventions for gastrointestinal conditions: A systematic review. Altern Ther Health Med 2002;8:76-83.

20. Koh CE, Young CJ, Young JM, Solomon MJ. Systematic review of randomized controlled trials of the effectiveness of biofeedback for pelvic floor dysfunction. Br J Surg 2008;95:1079-87.

21. Palsson OS, Heymen S, Whitehead W. Biofeedback treatment for functional anorectal disorders: A comprehensive efficacy review. Appl Psychophysiol Biofeedback 2004;29:153-74. 


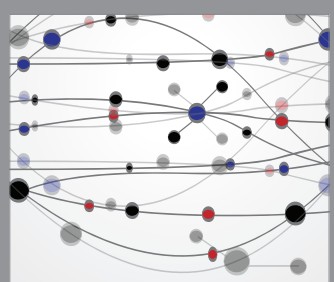

The Scientific World Journal
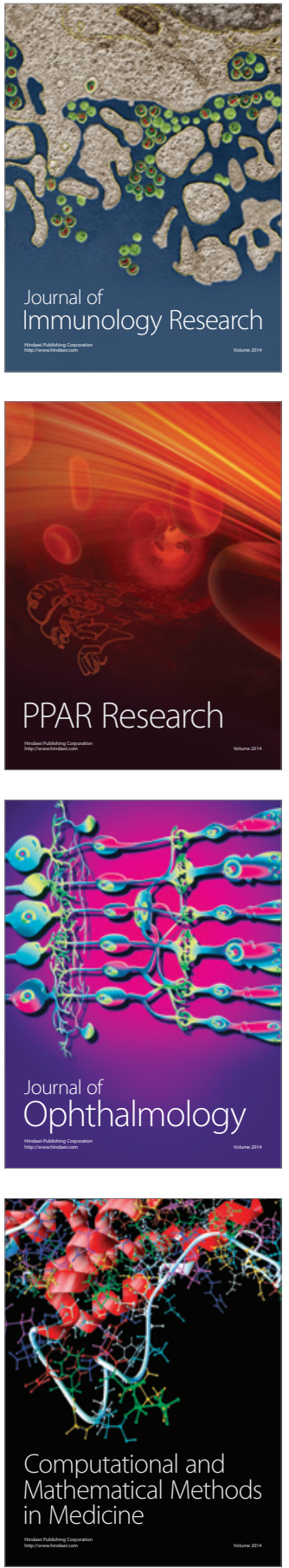

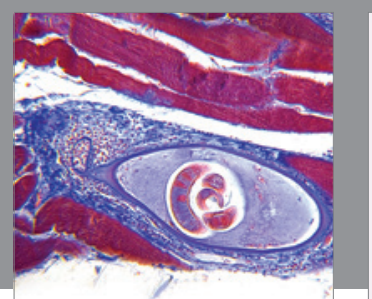

Gastroenterology Research and Practice

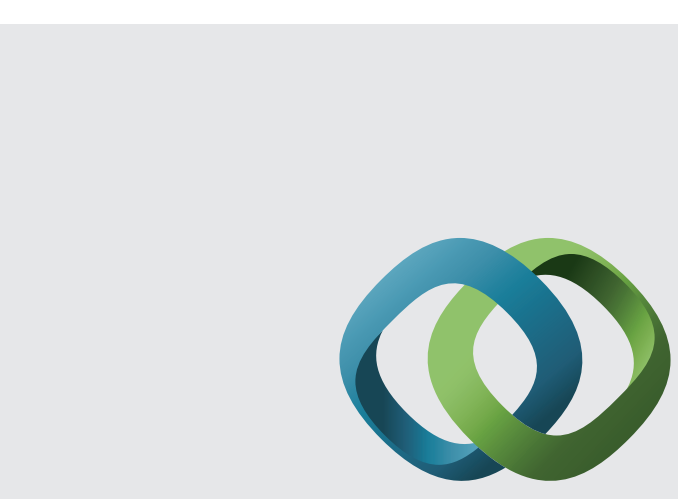

\section{Hindawi}

Submit your manuscripts at

http://www.hindawi.com
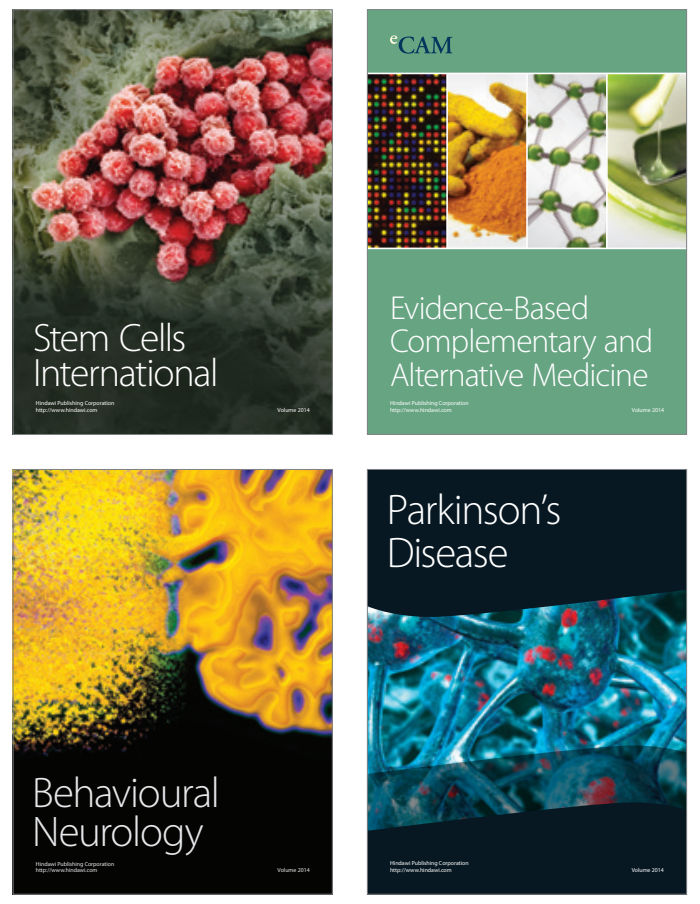
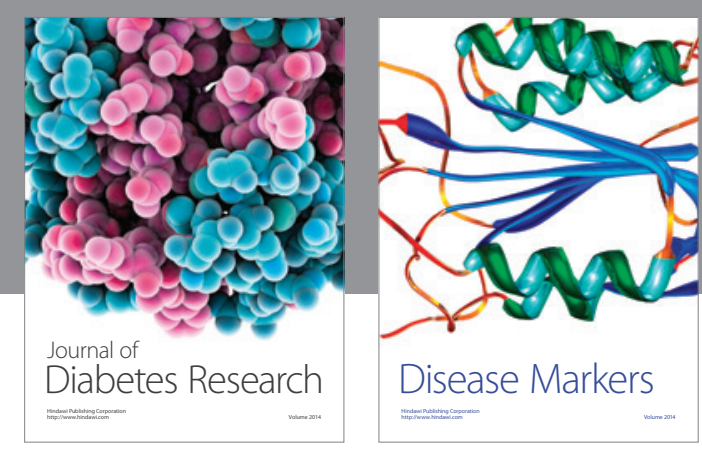

Disease Markers
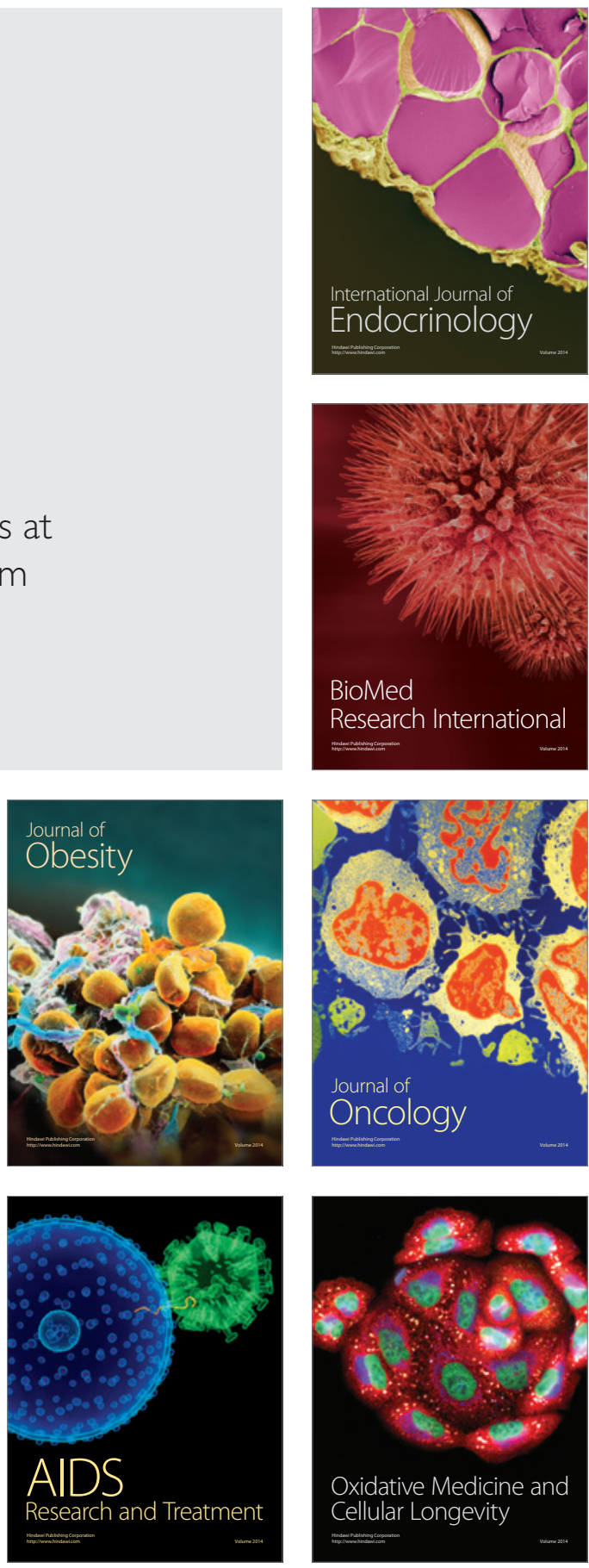